UDC 94(470.4)“19”+271.2

Submitted: 13.09 .2017

LBC 63.3(235.54)63-37+86.372

Submitted: 20.09.2017

\title{
THE VIEW OF CONTEMPORARY RESEARCHERS ON THE RELATIONSHIP BETWEEN THE STATE AND CHURCH IN THE SOUTH OF THE RSFSR DURING THE SECOND HALF OF THE $20^{\text {th }}$ CENTURY
}

\author{
Sergey P. Ramazanov \\ Volzhsky Institute of Humanities (Branch), Volgograd State University, Volzhsky, Russian Federation \\ Mariya I. Sokolova \\ Volzhsky Institute of Humanities (Branch), Volgograd State University, Volzhsky, Russian Federation
}

\author{
Alla V. Shadrina \\ Southern Scientific Center of RAS, Rostov-on-Don, Russian Federation
}

\begin{abstract}
The article offers a review of modern-day scientific research studies, which analyze the relationship between the state and church as well as general standing of the Russian Orthodox Church in the south of the RSFSR during the second half of the $20^{\text {th }}$ century. The article highlights the progress made in this field of research and shows the overall level of detalization of the topic.

There has been noticed a certain irregularity in the depth of scientific elaboration of the topic among separate territorial entities of the South of Russia. The works of local scientists and researchers from the clergy from different perspectives describe the events in the history of the eparchies and the evolution of the state to church relations in the Lower Volga region in the middle of the $20^{\text {th }}$ century. Major obstacles for the scientists are selective character of disclosure to the public of the materials from municipal archives and archives of governmental institutions, partial loss of the documents kept in the archives, absence of official statistical data about the population of church-goers and its religious identity, different level of detalization in the reports of the officials for the affairs of the Russian Orthodox Church and officials for religious affairs.

Local historians have not yet dwelt on the reasons for the changes in the church structure of the region or on the problems associated with implementation of church policy in separate locations and have not yet produced an objective evaluation of the outcomes of atheistic education of the youth and working people in the south of the RSFSR in the second half of the $20^{\text {th }}$ century. Lower Volga region.

Key words: historiography, Russian Orthodox Church, state and church relationship, Orthodox clergy, eparchy,

Citation. Ramazanov S.P., Sokolova M.I., Shadrina A.V. The View of Contemporary Researchers on the Relationship Between the State and Church in the South of the RSFSR During the Second Half of the $20^{\text {th }}$ Century. Vestnik Volgogradskogo gosudarstvennogo universiteta. Serija 4, Istorija. Regionovedenie. Mezhdunarodnye otnoshenija [Science Journal of Volgograd State University. History. Area Studies. International Relations], 2017, vol. 22, no. 4, pp. 172-177. (in Russian). DOI: https://doi.org/10.15688/jvolsu4.2017.4.17
\end{abstract}

УДК 94(470.4)“19”+271.2

ББК 63.3(235.54)63-37+86.372

Дата поступления статьи: 13.09.2017

Дата принятия статьи: 20.09.2017

\section{СОВРЕМЕННЫЕ ОТЕЧЕСТВЕННЫЕ ИССЛЕДОВАТЕЛИ О ГОСУДАРСТВЕННО-ЦЕРКОВНЫХ ОТНОШЕНИЯХ НА ЮГЕ РСФСР ВО ВТОРОЙ ПОЛОВИНЕ ХХ ВЕКА}

\section{Сергей Павлович Рамазанов}

Волжский гуманитарный институт (филиал) Волгоградского государственного университета, г. Волжский, Российская Федерация 


\section{Мария Игоревна Соколова}

Волжский гуманитарный институт (филиал) Волгоградского государственного университета, г. Волжский, Российская Федерация

\section{Алла Валерьевна Шадрина}

Южный научный центр РАН, г. Ростов-на-Дону, Российская Федерация

Аннотация. В статье анализируется современная научная литература, освещающая государственноцерковные отношения и положение Русской православной церкви на юге РСФСР во второй половине ХХ века. Выявлены достижения и общий уровень разработки данного вопроса.

Отмечена неравномерность научной разработанности проблемы в отдельных субъектах юга России. В трудах региональных светских и церковных исследователей в разной степени освещены отдельные сюжеты истории епархий и эволюции государственно-церковных отношений на Нижней Волге середины XX века. Серьезным препятствием на пути ученых стали: выборочный процесс рассекречивания фондов региональных и ведомственных архивов, частичная утрата документов в архивах, отсутствие официальной статистики численности верующих, указаний на их религиозную принадлежность, разный уровень информативности в отчетах уполномоченных по делам Русской православной церкви и уполномоченных по делам религий.

Вне поля зрения региональных историков остались причины изменения церковной структуры региона, проблема реализации церковной политики на местах и объективная оценка результатов атеистического воспитания молодежи и трудящихся на юге РСФСР во второй половине ХХ века.

М.И. Соколова провела выявление и систематизацию трудов современных авторов, посвященных изучению государственно-церковных отношений на юге РСФСР во второй половине ХХ века. С.П. Рамазанов проанализировал методологические подходы в работах региональных светских и церковных исследователей, осуществил общее научное редактирование статьи. А.В. Шадрина обобщила материалы, раскрывающие отдельные сюжеты внутрицерковной жизни и деятельности правящих архиереев православных епархий Нижневолжского региона.

Ключевые слова: историография, Русская православная церковь, государственно-церковные отношения, православное духовенство, епархия, Нижневолжский регион.

Цитирование. Рамазанов С. П., Соколова М. И., Шадрина А. В. Современные отечественные исследователи о государственно-церковных отношениях на юге РСФСР во второй половине ХХ века // Вестник Волгоградского государственного университета. Серия 4, История. Регионоведение. Международные отношения. -2017. - Т. 22, № 4. - C. 172-177. - DOI: https://doi.org/10.15688/jvolsu4.2017.4.17

Одной из актуальных проблем современной отечественной исторической науки является осмысление светскими и церковными историками реализации государственной церковной политики в СССР в центре и регионах, а также общественно-политической и духовной жизни послевоенного общества. Это обусловлено как интересом к недоступной для изучения на протяжении десятков лет тематике, так и тем, что Русская православная церковь (далее - РПЦ) занимает одну из ключевых позиций в современной нравственно-политической ситуации.

Начавшийся в годы перестройки новый этап в развитии отечественной историографии характеризуется переосмыслением традиционной концепции религиозной политики Советского Союза, расширением исследовательского поля, связанным с изучением рассекреченной документации и введением в научный обо- рот материалов закрытых фондов федеральных и региональных архивов РФ. Несмотря на всплеск интереса к данной теме в современной историографии, региональное направление остается по-прежнему перспективным.

Среди работ, посвященных общественно-политической, экономической, культурной и демографической ситуации на юге РСФСР во второй половине XX в., следует выделить труды историков Л.Ф. Васильевой, А.А. Гуменюка, Н.В. Кузнецовой, И.И. Панина, Ф.А. Хуснутдиновой $[1 ; 2 ; 5 ; 6 ; 11 ; 16]$. Они помогают понять противоречивую вероисповедную политику советской власти и умонастроения граждан, включая верующее население.

Важным шагом в изучении проблемы государственно-церковных отношений на Нижней Волге и Дону стала публикация двух сборников документов в 1998-2002 годах. Пер- 
вый - «Религиозные организации Нижней Волги и Дона в XX в.» подготовлен под руководством М.М. Загорулько. Выявление, систематизация, научное редактирование документов ГАВО и ЦДНИВО, характеризующих положение конфессий, существовавших на территории Царицынской (Сталинградской) губернии, Нижневолжского (Сталинградского) края, Сталинградской (Волгоградской) области в 1919-1986 гг., были осуществлены О.Ю. Редькиной, подготовившей также и вступительную статью к документальной части сборника [12]. Четырьмя годами позже вышел второй, значительно расширенный и дополненный сборник. В вводной статье О.Ю. Редькина уделила большое внимание характеристике положения религиозных объединений, существовавших в 1950-1980-е гг. на территории современной Волгоградской области (старообрядцев, евангельских христиан-баптистов, евреев, мусульман и пр.), практически не затрагивая положение РПЦ [13]. Следует отметить, что фактически Волгоградская область стала единственным субъектом Южного федерального округа, где исследователями истории Церкви были введены в научный оборот нормативные, делопроизводственные, статистические документы региональных советских и партийных органов, а также Царицынской (Сталинградской, Волгоградской) православных епархий.

Изучением истории епархий юга РСФСР второй половины XX в. занимались и священнослужители. Следует упомянуть второй том «Очерков истории Астраханской епархии...», в котором были представлены краткие биографические справки о деятельности архиереев, когда-либо возглавлявших Астраханскую епархию в 1902-2002 гг., собранные и систематизированные игуменом Иосифом (Марьяном) [10].

Первым крупным исследованием, посвященным истории православных приходов Краснодарского края, является коллективный сборник под редакцией О.В. Матвеева [3]. В главе «Приходы советской Кубани», написанной А.Н. Бабич и С.Н. Рыбко на основе материалов государственного архива Краснодарского края, акцентируется внимание на становлении и развитии православных приходов г. Краснодара и отдельных станичных прихо- дов края, приводятся краткие биографические сведения их настоятелей. При этом вопросы материального положения Краснодарской и Кубанской епархии, меры воздействия местных властей на сознание верующих Кубани не рассматривались. Весьма фрагментарно представлены данные о количестве совершаемых православной церковью религиозных треб и обрядов в Краснодарском крае во второй половине XX века.

В начале 2000-х гг. в трудах региональных историков значительно расширяется круг вопросов, появляются новые сюжеты. В частности, изучению биографий правящих архиереев, духовенства и верующих, их вклада в сохранение и укрепление позиций Церкви в Нижневолжском регионе посвящены работы С.М. Иванова, В.И. Супруна, С.П. Чибисовой $[4 ; 17]$. Данным работам присуща ограниченность источниковой базы и публицистический стиль.

Стоит отметить работы Н.Н. Силина и А.В. Шадриной, в которых раскрываются отдельные сюжеты внутрицерковной жизни Ростовской и Саратовской епархии под руководством митрополита Вениамина (Федченкова) в 1951-1958 годах. Используя материалы государственного архива Ростовской области, исследователи воссоздали картину приходской жизни изучаемых епархий и дали оценку сложившимся отношениям между митрополитом и областными уполномоченными $[14 ; 18$; 19]. До настоящего времени проблема государственно-церковных отношений во второй половине XX в. в Ростовской области не становилась предметом изучения светских и церковных историков.

Проведенный анализ тематики диссертационных исследований, посвященных изучению государственно-церковных отношений на юге РСФСР во второй половине XX в., показал, что их хронологические рамки, как правило, охватывают незначительные временные промежутки (3 из 5 диссертаций). Другой тенденцией региональной историографии является преобладание работ, раскрывающих отношения советского государства и Церкви (3 из 5), по сравнению с трудами по истории отдельных епархий (2 из 5) [7; 8; 9; 14; 15].

Среди основных достижений современной региональной историографии можно вы- 
делить: подробный анализ отношений высшего духовенства с советскими чиновниками различного уровня; состояние церковной организации в отдельных епархиях Нижневолжского региона; оценка уровня религиозности населения; детальное рассмотрение частных проблем церковной истории.

В настоящее время исследование государственно-церковных отношений на юге РСФСР во второй половине XX в. продолжается, а два научных направления (светское и церковное), сформировавшиеся в региональной историографии проблемы, плодотворно и активно развиваются.

\section{СПИСОК ЛИТЕРАТУРЫ}

1. Васильева, Л. Е. Роль женщины в социально-экономической и политической сферах жизни советского общества в 1945-1965 гг. : дис. ... канд. ист. наук : 07.00.02 / Васильева Лариса Ефимовна. Саратов, 2004. $-247 \mathrm{c}$.

2. Гуменюк, А. А. Социальная политика и практика Советского государства в 1953-1985 годы (на материалах Нижнего Поволжья) / А. А. Гуменюк. - Саратов : Изд-во Сарат. ун-та, 2016. -258 с.

3. Дело мира: история культуры и православия на Кубани / науч. ред. О. В. Матвеев. - Краснодар : Православный Екатеринодар : Традиция, 2009. $-304 \mathrm{c}$.

4. Иванов, С. М. Православие на волгоградской земле: епархии и епископы / С. М. Иванов, В. И. Супрун. - Волгоград : Изд-во ВГИПК РО, 2002. - Ч. 2. $-136 \mathrm{c}$.

5. Кузнецова, Н. В. Восстановление и укрепление материальной базы культурно-просветительных учреждений Сталинградской области в 1943-1953 гг. / Н. В. Кузнецова // Вестник Волгоградского государственного университета. Серия 4, История. Регионоведение. Международные отношения. - 2014. № 1(25). - C. 70-78. - DOI: http://dx.doi.org/10.15688/ jvolsu4.2014.1.9.

6. Кузнецова, Н. В. Нижнее Поволжье в 1945 1953 гг:: социальные проблемы послевоенного восстановления и развития / Н. В. Кузнецова. - Волгоград : Волгогр. науч. изд-во, 2010. - 221 с.

7. Курышова, Л. В. Женские монастыри России: своеобразие культурных традиций (на примере монастырей Волгоградской области) : дис. ... канд. ист. наук : 24.00 .01 / Курышова Людмила Вениаминовна. - Волгоград, 2010. -289 с.

8. Мордвинов, С. В. Русская православная церковь на Нижней Волге и Дону в 1941-1953 гг.: возрождение социокультурных традиций : дис. ... канд. ист. наук : 24.00.01 / Мордвинов Сергей Валерьевич. - Волгоград, 2014. - $309 \mathrm{c}$.

9. Наумов, С., иеродиак. История Волгоградской епархии в советский период (1917-1991 гг.). : автореф. дис. ... канд. богословия / Наумов Серафим. - Сергиев Посад, 2008. - 20 с.

10. Очерки истории Астраханской епархии за 400 лет ее существования : в 2 т. Т. 2. Очерки истории Астраханской епархии с 1902 по 2002 г. - Ростов н/Д : Фолиант, 2002. - 578 с.

11. Панин, И. И. Стратегия развития Астраханской области в годы послевоенных пятилеток (19451970) / И. И. Панин, И. И. Панина. - Астрахань : Волга, 2007.- $143 \mathrm{c}$.

12. Редькина, О. Ю. Религиозная ситуация в регионе (по материалам архивов Волгоградской области) / О. Ю. Редькина // Религиозные организации Нижней Волги и Дона в XX веке : сб. документов / сост. О. Ю. Редькина, Т. А. Савина ; под ред. М. М. Загорулько. - Волгоград : Изд-во ВолГУ, 1998. - С. 8-38.

13. Редькина, О. Ю. Религиозная ситуация в регионе в 1917-1986 гг.: по материалам архивов Волгоградской области / О. Ю. Редькина // Государство и религиозные организации Нижней Волги и Дона в XX веке : сб. документов и материалов, каталог культовых зданий / сост. О. Ю. Редькина, Т. А. Савина ; под ред. М. М. Загорулько. - Волгоград : Издатель, 2002. - С. 9-62.

14. Силин, Н. Н. Жизнь и деятельность митрополита Вениамина (Федченкова) в 1948-1961 гг. в контексте церковно-государственных отношений : автореф. дис. ... канд. богословия / Силин Никита Николаевич. - Сергиев Посад, 2010. - 22 с.

15. Соколова, М. И. Советское государство и Русская православная церковь в 1953-1964 гг. : на материалах Сталинградской (Волгоградской) области : дис. ... канд. ист. наук : 07.00.02 / Соколова Мария Игоревна. - Волгоград, 2016. - 357 с.

16. Хуснутдинова, Ф. А. Население Сталинградской области в 1939-1959 гг:: демографический аспект / Ф. А. Хуснутдинова // Стрежень : науч. ежегод. / под ред. М. М. Загорулько. - Волгоград. 2009. - Вып. 7. - С. 357-360.

17. Чибисова, С. П. История Донской (Ростовской-на-Дону) епархии в биографиях архипастырей / С. П. Чибисова. - Ростов н/Д : Изд-во Ростовской н/Д епархии, 2006. -223 с.

18. Шадрина, А. В. Личность митрополита Вениамина (Федченкова) в документах государственного архива Ростовской области / А. В. Шадрина // Научные труды Донской духовной семинарии. Ростов н/Д : Антей, 2016. - Вып. 5. - С. 132-143.

19. Шадрина, А. В. Особенности формирования клира Ростовской и Таганрогской (Новочеркасской) епархии в 1940-1950-х гг. / А. В. Шадрина // Научная мысль Кавказа. - 2016. -№ 1 (85). - С. 98-103. 


\section{REFERENCES}

1. Vasileva L.F. Rol zhenshchiny $v$ sotsialnoekonomicheskoy i politicheskoy sferakh zhizni sovetskogo obshchestva v 1945-1965 gg.: dis. ... kand. ist. nauk [The Role of a Woman in Socio-Economic and Political Life of the Soviet People in 1945-1965. Cand. hist. sci. diss.]. Saratov, 2004. 247 p.

2. Gumeniuk A.A. Sotsialnaya politika $i$ praktika Sovetskogo gosudarstva v 1953-1985 gody (na materialakh Nizhnego Povolzhya) [Social Politics and Practice in the Soviet State in 1953-1985 (Based on the Data of the Lower Volga Region)]. Saratov, SGU Publ., 2016. 258 p.

3. Delo mira: istoriya kultury i pravoslaviya na Kubani [Case of Peace: History of Culture and Orthodox Christianity in Kuban]. Krasnodar, Orthodox Ekaterinodar Publ.; Tradition Publ., 2009. 304 p.

4. Ivanov S.M. Pravoslavie na volgogradskoi zemle: eparkhii i episkopy [Orthodox Christianity in the Volgograd Region: Eparchies and Bishops]. Volgograd, VGIPK RO Publ., 2002, Part 2. 136 p.

5. Kuznetsova N.V. Vosstanovlenie i ukreplenie materialnoi bazy kulturno-prosvetitelnykh uchrezhdenii Stalingradskoi oblasti v 1943-1953 gg. [Rehabilitation and Consolidation of the Material Base of the Cultural and Educational Institutions in the Stalingrad Region in 1943-1953]. Vestnik Volgogradskogo gosudarstvennogo universiteta. Seriya 4, Istoriya. Regionovedenie. Mezhdunarodnye otnosheniya [Science Journal of Volgograd State University. History. Area Studies. International Relations], 2014, no. 1, pp. 70-78. DOI: http:// dx.doi.org/10.15688/jvolsu4.2014.1.9.

6. Kuznetsova N.V. Nizhnee Povolzhye v 1945 1953 gg.: sotsialnye problemy poslevoennogo vosstanovleniya i razvitiya [Lower Volga Region in 1945-1953: Social Challenges of the Post-War Recovery and Development]. Volgograd, Volgogradskoe nauch. izd-vo, 2010. $221 \mathrm{p}$.

7. Kuryshova L.V. Zhenskie monastyri Rossii: svoeobrazie kulturnykh traditsii (na primere monastyrey Volgogradskoy oblasti): dis. ... kand. ist. nauk [Convents in Russia: Unique Cultural Traditions (Example of the Volgograd Region Convents). Cand. hist. sci. diss.]. Volgograd, 2010. 289 p.

8. Mordvinov S.V. Russkaia pravoslavnaia tserkov na Nizhney Volge i Donu v 1941-1953 gg.: vozrozhdenie sotsiokulturnykh traditsiy: dis. ... kand. ist. nauk [Russian Orthodox Church in the Lower Volga and Don regions in 1941-1953: revival of socio-cultural traditions. Cand. hist. sci. diss.]. Volgograd, 2014. 309 p.

9. Naumov Serafim, ierodiak. Istoriya Volgogradskoy eparkhii v sovetskiy period (19171991 gg.): avtoref. diss. ... kand. bogosloviya [History of the Volgograd Eparchy during the Soviet Period (1917-1991). Cand. theolog. sci. diss.]. Sergiev Posad, 2008. 20 p.

10. Ocherki istorii Astrakhanskoy eparkhii za 400 let ee sushchestvovaniya: v 2 t. T. 2. Ocherki istorii Astrakhanskoy eparkhii s 1902 po 2002 g. [Essays on the 400 years of the history of the Astrakhan Eparchy. In 2 vols. Vol. 2. Essays on the History of the Astrakhan Eparchy from 1902 to 2002]. Rostov-onDon, Foliant Publ., 2002. 578 p.

11. Panin I.I. Strategiia razvitiya Astrakhanskoy oblasti $v$ gody poslevoennykh pyatiletok (19451970) [Strategy of the Post-War Development of the Astrakhan Region in Five-Year Plans (1945-1970)]. Astrakhan, Volga Publ., 2007. 143 p.

12. Redkina O.Yu. Religioznaya situatsiya $v$ regione (po materialam arkhivov Volgogradskoi oblasti) [Religion of the Region (Based on the Archives of the Volgograd region)]. Religioznye organizatsii Nizhney Volgi i Dona $v$ XX veke: sbornik dokumentov [Religious Institutions in the Low Volga and Don Regions in the $20^{\text {th }}$ Century: Collection of Documents]. Volgograd, Izd-vo VolGU., 1998, pp. 8-38.

13. Redkina O.Yu. Religioznaya situatsiya v regione v 1917-1986 gg.: po materialam arkhivov Volgogradskoy oblasti [The Role of Religion in the Region in 1917-1986 (Based on the Archives of the Volgograd Region)]. Gosudarstvo i religioznye organizatsii Nizhnei Volgi i Dona v XXveke: sbornik dokumentov $i$ materialov, katalog kultovykh zdanii [State and Religious Institutions in the Lower Volga and Don Regions in the $20^{\text {th }}$ Century: Collection of Documents and Materials, a List of Religious Buildings]. Volgograd, Izdatel Publ., 2002, pp. 9-62.

14. Silin N.N. Zhizn i deiatelnost mitropolita Veniamina (Fedchenkova) v 1948-1961 gg. v kontekste tserkovno-gosudarstvennykh otnosheniy: avtoref. diss. ... kand. bogosloviya [Life and Work of Metropolitan Veniamin (Fedchenkov) in 1948-1961 in the Light of the Church-State Relations. Cand. theolog. sci. diss.]. Sergiev Posad, 2010. 22 p.

15. Sokolova M.I. Sovetskoe gosudarstvo $i$ Russkaya pravoslavnaya tserkov v 1953-1964 gg.: na materialakh Stalingradskoy (Volgogradskoy) oblasti: dis. ... kand. ist. nauk [Soviet State and Russian Orthodox Church in 1953-1964 (Based on the Materials of the Stalingrad (Volgograd) Region). Cand. hist. sci. diss.]. Volgograd, 2016. 357 p.

16. Khusnutdinova F.A. Naselenie Stalingradskoy oblasti v 1939-1959 gg.: demograficheskiy aspekt [Population of the Stalingrad Region in 1939-1959: Demographic Details]. Strezhen: nauchnyy ezhegodnik [Strezhen: Scientific Yearbook], 2009, no. 7, pp. 357-360.

17. Chibisova S.P. Istoriya Donskoy (Rostovskoyna-Donu) eparkhii $v$ biografiyakh arkhipastyrey 
[History of the Don (Rostov-on-Don) Eparchy in Biographies of Arch-Flamens]. Rostov-on-Don, Rostovon-Don bishopric Publ., 2006. 223 p.

18. Shadrina A.V. Lichnost mitropolita Veniamina (Fedchenkova) v dokumentakh Gosudarstvennogo arkhiva Rostovskoy oblasti [Personality of Metropolitan Veniamin (Fedchenkov) as Traced in the Documents of the State Archives of the Rostov Region]. Nauchnye trudy Donskoy dukhovnoy seminarii [Scientific Works of the Don Theological Seminary]. Rostov-on-Don, Antei Publ., 2016, no. 5, pp. 132-143.

19. Shadrina A.V. Osobennosti formirovaniya klira Rostovskoi i Taganrogskoy (Novocherkasskoy) eparkhii v 1940-1950 gg. [Peculiar Traits of the Clergy Formation in the Rostov and Taganrog (Novocherkassk) Eparchies in 1940-1950]. Nauchnaya mysl Kavkaza, 2016, no. 1 (85), pp. 98-103.

\section{Information about the Authors}

Sergey P. Ramazanov, Doctor of Sciences (History), Professor, Leading Researcher, Volzhsky Institute of Humanities (Branch), Volgograd State University, 40 let Pobedy St., 11, 404133 Volzhsky, Russian Federation, ramasergej@gmail.com, http://orcid.org/0000-0001-7942-2852

Mariya I. Sokolova, Candidate of Sciences (History), Document Specialist, Volzhsky Institute of Humanities (Branch), Volgograd State University, 40 let Pobedy St., 11, 404133 Volzhsky, Russian Federation,ob.otdel@vgi.volsu.ru, http://orcid.org/0000-0003-2805-3377

Alla V. Shadrina, Candidate of Sciences (History), Researcher, Southern Scientific Center of RAS, Prosp. Chekhova, 41, 344006 Rostov-on-Don, Russian Federation, shadrina@ssc-ras.ru, http:// orcid.org/0000-0002-1925-0216

\section{Информация об авторах}

Сергей Павлович Рамазанов, доктор исторических наук, профессор, ведущий научный сотрудник, Волжский гуманитарный институт (филиал) Волгоградского государственного университета, ул. 40 лет Победы, 11, 404133 г. Волжский, Российская Федерация, ramasergej@gmail.com, http://orcid.org/0000-0001-7942-2852

Мария Игоревна Соколова, кандидат исторических наук, документовед, Волжский гуманитарный институт (филиал) Волгоградского государственного университета, ул. 40 лет Победы, 11, 404133 г. Волжский, Российская Федерация, ob.otdel@vgi.volsu.ru, http://orcid.org/0000-00032805-3377

Алла Валерьевна Шадрина, кандидат исторических наук, научный сотрудник, Южный научный центр РАН, просп. Чехова, 41, 344006 г. Ростов-на-Дону, Российская Федерация, shadrina@ssc-ras.ru, http://orcid.org/0000-0002-1925-0216 